\title{
Mortality experience of employees exposed to 2-mercaptobenzothiazole at a chemical plant in Nitro, West Virginia
}

\author{
Marcie E Strauss, Elizabeth D Barrick, Roy M Bannister
}

\begin{abstract}
Mortality trends for 1059 production workers at a rubber chemicals plant in Nitro, West Virginia were examined to find whether they had increased mortality from cancer associated with exposure to 2-mercaptobenzothiazole (MBT). This chemical and its derivatives are vulcanising agents that have been manufactured at the plant since 1935. Analyses were conducted on MBT exposed employees by cumulative exposure and time since first exposure, and were also stratified by past assignment to $p$-aminobiphenyl (PAB) related departments; PAB is a potent bladder carcinogen that was used at the plant between 1935 and 1955. There was an excess of bladder cancer in MBT workers who had PAB related assignments (standardised mortality ratio $(\mathrm{SMR})=3200,95 \%$ confidence interval $(95 \%$ CI) 1286-6593). In employees without a job assignment with exposure to $\mathrm{PAB}$, there were no associations between exposure to MBT and increased rates of most malignant neoplasms. The SMR for bladder cancer was increased based on three deaths (SMR $=455,95 \%$ CI 94-1328), although these results were too few to evaluate trends by cumulative exposure category. The possibility of confounding by PAB for exposures for jobs that covered all areas of the plant for these three cases must be considered in the light of the potency of PAB as a bladder carcinogen. There were no deaths from bladder cancer among MBT workers hired after the end of manufacture and use of PAB, but the expected number of deaths was only $0 \cdot 03$.
\end{abstract}

(British Fournal of Industrial Medicine 1993;50:888-893)

Monsanto Company, St Louis, Missouri

M E Strauss, $R$ M Bannister

Scott Depot, West Virginia

E D Barrick
A study by the National Toxicology Program (NTP) reported the results of a chronic gavage study with 2-mercaptobenzothiazole (MBT) in rats and mice. ${ }^{1}$ Some evidence of carcinogenic activity was reported for male and female rats. The study reported no increased incidences of tumours in male mice and the findings in female mice were equivocal. A second chronic feeding study with MBT in mice showed no neoplastic effects related to treatment. ${ }^{2}$ The findings in the Program studies were not considered sufficient to list MBT on the Department of Health and Human Services Annual Report on Carcinogens. ${ }^{3}$

Because the animal studies on MBT were inconclusive, investigations of workers exposed to MBT were initiated at a manufacturing plant in Nitro, West Virginia, and a similar plant in North Wales, United Kingdom. ${ }^{4}$ Both plants had long histories of MBT manufacture and use. We report the results for the study of workers in West Virginia.

\section{Materials and methods}

DATA COLLECTION METHODS

The study population included 1059 full time, white, male production employees who were paid an hourly rate and who were active at the Nitro plant between 1955 and 1977 for one day or more. Workers who left before 1955 were not included because many of the early personnel records were missing from the plant files. The study population was enumerated from a computerised plant payroll file and social security tax records. Information on demographic and work history was taken from plant personnel records. Five employees with missing or incomplete work histories were not included. Salaried personnel were excluded because many had limited exposures to the plant environment and many of their work histories could not be ascertained from plant records. Thirty one female and 32 non-white male employees were excluded because of small numbers.

Vital status to the end of 31 December, 1987 
was obtained for $98 \%$ of the 1059 employees eligible for the study. Death certificates were available for all but one known death. At the end of the follow up period, 769 employees $(73 \%)$ were verified as living, $271(26 \%)$ were confirmed dead, and $18(2 \%)$ were lost to follow up. Information on vital status was obtained from the company payroll, pension and mortality databases, the Social Security Administration, the National Death Index, the Motor Vehicle Bureau of West Virginia, and credit bureau records. Underlying cause of death was coded by two independent nosologists according to the rules of the eighth revision of the International Classification of Diseases (adapted). ${ }^{5}$ Discrepancies were resolved by discussions between the two nosologists.

\section{EXPOSURE ASSESSMENT METHODS}

Production of MBT at the Nitro plant began in 1934 and continues at present. The manufacturing process has been constant, combining aniline, sulphur, and carbon disulphide to produce MBT. Hydrogen sulphide is a significant byproduct. Over the years, various grades of MBT have been produced; MBT has been purified and sold as a rubber accelerator or converted to the sodium salt, which is an intermediate in the production of other rubber accelerators (table 1). There is some evidence that the amino substituted MBT derivatives are metabolised to MBT and the corresponding amine in vivo. ${ }^{67}$ Therefore, it was assumed that exposure to $1 \mathrm{mg} / \mathrm{m}^{3}$ of an MBT derivative was biologically equivalent to exposure to $1 \mathrm{mg} / \mathrm{m}^{3}$ MBT.

Employees were considered exposed if they had jobs with potential exposure to MBT dust or any of the MBT related derivatives. Animal studies have indicated a minimal potential for human dermal absorption, so dermal exposure to the dry product was not thought to be an important route of entry. ${ }^{78}$ Annual air borne exposure estimates throughout the study period were developed for all hourly production jobs by a former plant industrial hygienist with sampling data available from 1977 to 1989, historical company documents, and inter- views with knowledgeable retirees for the period before 1977. All jobs with potential exposure to MBT were assigned to one of four exposure categories: very low $\left(>0\right.$ to $\left.0.5 \mathrm{mg} / \mathrm{m}^{3}\right)$, low $(>0.5$ to $\left.2.0 \mathrm{mg} / \mathrm{m}^{3}\right)$, medium $\left(>2.0\right.$ to $\left.5.0 \mathrm{mg} / \mathrm{m}^{3}\right)$, and high ( $>5.0$ to $20.0 \mathrm{mg} / \mathrm{m}^{3}$ ). A cumulative exposure index for each job was calculated by multiplying the midpoint of each exposure category by duration in an MBT exposed job. Altogether, 600 of 1059 employees had a history of exposure to MBT. General maintenance, production, and pilot plant jobs could not be classified conclusively and were considered unexposed.

Because of concern about the potential confounding effect of exposure to para-aminobiphenyl (PAB), a potent human bladder carcinogen used at the plant between 1935 and $1955,9^{10}$ we also identified employees who worked in a PAB related department. The employees exposed to PAB were defined as those employees who worked in certain areas of the plant where PAB had been used. Those employees whose work covered all parts of the plant, such as yard labour, maintenance, or general production jobs were not considered exposed to PAB, although it was recognised that some of these jobs may have involved such exposure.

\section{ANALYTICAL METHODS}

A cohort study design was used to compare death rates of workers with rates for the general population. Standardised mortality ratios (SMRs) were calculated by taking the ratio of observed deaths to expected deaths multiplied by $100 .{ }^{11}$ Person-years of follow up were counted from 1955 to the date of death or the study end date, 1987 , whichever came first.

Mortality for the white male populations of the counties located within a 20 mile radius of the plant and of the United States as a whole were used to calculate expected death rates. Precision of the SMRs were found with approximate $95 \%$ confidence intervals $(95 \% \mathrm{CIs})$ when the number of observed deaths exceeded five, and Fisher's exact $95 \%$ CIs in all other instances. ${ }^{12}$

Table 1 Derivatives of $M B T$ included in study

\begin{tabular}{llc}
\hline Chemical name & CAS No & $\begin{array}{l}\text { Start and stop } \\
\text { production dates }\end{array}$ \\
\hline 2-Mercaptobenzothiazole & 000149304 \\
Sodium mercaptobenzothiazole & 002492264 \\
n-Cyclohexyl-2-benzothiazole sulphenamide & 000095330 \\
Benzothiazyl disulphide & 000120785 \\
n-Tertiary-butyl-2-benzothiazole sulphenamide & 000095318 \\
2-(morpholinothio) Benzothiazole & 000102772 & $1937-$ present \\
2-(2,6-dimethylmorpholinothio) Benzothiazole & 000102783 \\
2-(hexamethyleneiminothio) Benzothiazole & 016832625 \\
1,3 Bis(2-benzothiazolylmercaptomethyl) urea & CAS number \\
& not available \\
\hline
\end{tabular}


The SMRs were calculated for the total plant population and the subgroup exposed to MBT. To evaluate potential confounding from $\mathrm{PAB}$, the cohort exposed to MBT was stratified by those with and those without a PAB job assignment. The SMRs were also calculated for MBT exposed workers hired after 1955, the year after use of PAB at the plant was discontinued.

Cumulative exposure analyses were conducted for the subgroup of workers exposed to MBT without job assignments in the PAB areas. The SMRs that were based on three or more deaths were evaluated for an internal comparison population without exposure to MBT or PAB according to our definitions, and three categories of cumulative exposure to MBT (<2 mg/m $3 \mathrm{~m}^{3} 2-7 \mathrm{mg} / \mathrm{m}^{3}, 8-129$ $\left.\mathrm{mg} / \mathrm{m}^{3}\right)$. These categories are subsequently referred to as low, medium, and high. The cumulative exposure categories were developed by dividing the person-years into three nearly equal groups and with the upper and lower cumulative exposure value of each group. Trend tests were used to find whether rates of disease increased with exposure level. ${ }^{13}$ Death rates were also evaluated for time since first exposure ( $<20$ and $\geqslant 20$ years).

Direct comparisons of cancer rates used MantelHaenszel techniques for estimation of the age adjusted rate ratio $\left(R R_{M-H}\right)$, with $95 \%$ CIs based on the variance of the natural logarithm of the $\mathrm{RR}_{\mathrm{M}-\mathrm{H} \cdot{ }^{13}}$ The data were stratified into four age categories (15-34 years, 35-54 years, 55-64 years, and 65 or more years). Trend tests were also used. ${ }^{13}$

The unexposed employees in the plant wide cohort became part of an internal comparison population that was used for developing baseline mortalities.

\section{Results}

A comparison of results with local $v$ United States population rates showed small differences. Therefore, the tables include results from comparisons with the local population. Table 2 shows SMRs for all workers for 1955-1987. Mortality from all causes was significantly lower than local mortality $(S M R=87$, Obs $=272,95 \%$ CI 77-98), whereas the SMR for all cancers was slightly raised at 118 (Obs $=78,95 \%$ CI 93-147). This was attributable to the raised rates seen for lung cancer $(\mathrm{SMR}=122, \mathrm{Obs}=32,95 \% \mathrm{CI} 83-172)$, prostate cancer $(S M R=180$, Obs $=7,95 \%$ CI $72-370)$, and bladder cancer $(S M R=797$, Obs $=13,95 \%$ CI 424-1363). SMRs for other site specific cancers and for non-neoplastic diseases were either near or considerably lower than 100 .

Table 3 shows SMRs calculated for the total subcohort exposed to MBT, and then by PAB exposure state. Table 3 also shows that mortality from all causes in the total MBT subcohort was slightly lower than local mortality, (SMR $=90$, Obs $=158,95 \%$ CI 76-105), whereas the SMR for all cancers was slightly raised at 119 (Obs $=46$, $95 \%$ CI 87-158). Increased death rates were seen for lung cancer $(\mathrm{SMR}=132, \mathrm{Obs}=21,95 \% \mathrm{CI}$ 82-202), prostate cancer $(S M R=201$, Obs $=4$, 95\% CI 55-514), and bladder cancer (SMR =

Table 2 Standardised mortality ratios and observed (Obs) and expected (Exp) number of cause specific deaths during 1955-1987 for white hourly employees

\begin{tabular}{|c|c|c|}
\hline Causes of death (ICD-8) & $S M R(O b s / E x p)$ & $(95 \% \mathrm{Cl})$ \\
\hline $\begin{array}{l}\text { All causes (0-999) } \\
\text { All cancers (140-209): } \\
\text { Buccal cavity and pharyngeal (140-149) } \\
\text { Oesophageal (150) } \\
\text { Stomach (151) } \\
\text { Colon (153) } \\
\text { Rectal }(154) \\
\text { Liver (155-156) } \\
\text { Pancreatic (157) } \\
\text { Lung (162) } \\
\text { Prostate }(185) \\
\text { Kidney (189-0-189-2) } \\
\text { Bladder (188, 189.9) } \\
\text { Central nervous system (191-192) } \\
\text { Leukaemia (204-207) } \\
\text { All other cancers } \\
\text { Ischaemic heart disease (410-414) } \\
\text { Cerebrovascular disease (430-438) } \\
\text { Non-malignant respiratory disease (460-519): } \\
\text { Bronchitis, emphysema, and asthma (490-493) } \\
\text { Other non-malignant respiratory disease (460-466, 500-519) } \\
\text { External causes (800-999) } \\
\text { All other causes } \\
\text { Unknown causes }\end{array}$ & $\begin{array}{c}87(272 / 313 \cdot 56) \\
118(78 / 66 \cdot 35) \\
64(1 / 1 \cdot 57) \\
-(0 / 1 \cdot 56) \\
45(1 / 2 \cdot 25) \\
63(3 / 4 \cdot 79) \\
73(1 / 1 \cdot 38) \\
98(1 / 1 \cdot 03) \\
33(1 / 3 \cdot 04) \\
122(32 / 26 \cdot 26) \\
180(7 / 3 \cdot 90) \\
-(0 / 1 \cdot 63) \\
797(13 / 1 \cdot 63) \\
63(1 / 1 \cdot 58) \\
85(2 / 2 \cdot 36) \\
112(15 / 13 \cdot 37) \\
107(116 / 108 \cdot 80) \\
49(9 / 18 \cdot 44) \\
59(13 / 22 \cdot 11) \\
37(2 / 5 \cdot 41) \\
104(9 / 8 \cdot 67) \\
72(22 / 30 \cdot 49) \\
49(33 / 67 \cdot 37) \\
1\end{array}$ & $\begin{array}{c}(77-98) \\
(93-147) \\
(2-354) \\
(0-237) \\
(1-248) \\
(13-183) \\
(2-404) \\
(2-543) \\
(1-183) \\
(83-172) \\
(72-370) \\
(0-226) \\
(424-1363) \\
(2-353) \\
(10-306) \\
(63-185) \\
(88-128) \\
(22-93) \\
(31-101) \\
(5-133) \\
(48-197) \\
(45-109) \\
(34-69)\end{array}$ \\
\hline
\end{tabular}

No of employees $=1059$; person-years $=23943$ and includes five employees with missing work histories. 
Table 3 Standardised mortality ratios and observed and expected numbers of cause specific deaths during 1955-1987 for white hourly male employees exposed to $M B T$ and stratified by $P A B$ exposure

\begin{tabular}{|c|c|c|c|c|c|c|c|c|}
\hline \multirow{2}{*}{$\begin{array}{l}\text { Causes } \\
\text { of death }\end{array}$} & \multicolumn{2}{|c|}{$\begin{array}{l}\text { Total MBT cohort } \\
(n=600, p-y=13760)\end{array}$} & \multicolumn{2}{|c|}{$\begin{array}{l}\text { MBT with } \\
P A B \text { job assignment } \\
(n=89, p-y=2161)\end{array}$} & \multicolumn{2}{|c|}{$\begin{array}{l}\text { MBT without } \\
P A B \text { job assignment } \\
(n=511, p-y=11599)\end{array}$} & \multicolumn{2}{|c|}{$\begin{array}{l}\text { MBT employees } \\
\text { hired after } 1955 \\
(n=270, p-y=5104)\end{array}$} \\
\hline & $S M R$ (obs/exp) & $(95 \% \mathrm{Cl})$ & $S M R(o b s / e x p)$ & $(95 \% \mathrm{Cl})$ & $S M R$ (obs/exp) & $(95 \% C l)$ & $S M R$ (obs/exp) & $(95 \% \mathrm{Cl})$ \\
\hline $\begin{array}{l}\text { All causes } \\
\text { All cancers } \\
\text { Large }\end{array}$ & $\begin{array}{r}90(158 / 176 \cdot 17) \\
119(46 / 38 \cdot 81)\end{array}$ & $\begin{array}{l}(76-105) \\
(87-158)\end{array}$ & $\begin{array}{l}134(52 / 38 \cdot 87) \\
238(20 / 8 \cdot 41)\end{array}$ & $\begin{array}{l}(100-175) \\
(145-367)\end{array}$ & $\begin{array}{l}77(106 / 137 \cdot 29) \\
86(26 / 30 \cdot 40)\end{array}$ & $\begin{array}{l}(63-93) \\
(56-125)\end{array}$ & $\begin{array}{l}37(8 / 21 \cdot 81) \\
-(0 / 4 \cdot 26)\end{array}$ & $\begin{array}{l}(16-72) \\
(0-87)\end{array}$ \\
\hline $\begin{array}{l}\text { intestine } \\
\text { Rectal } \\
\text { Liver } \\
\text { Lung } \\
\text { Prostate } \\
\text { Bladder } \\
\text { Leukaemia }\end{array}$ & $\begin{array}{c}37(1 / 2 \cdot 73) \\
126(1 / 0 \cdot 80) \\
166(1 / 0 \cdot 60) \\
132(21 / 15 \cdot 92) \\
201(4 / 1 \cdot 99) \\
1138(10 / 0 \cdot 88)\end{array}$ & $\begin{array}{c}(1-204) \\
(3-700) \\
(4-925) \\
(82-202) \\
(55-514) \\
(546-2093)\end{array}$ & $\begin{array}{c}-(0 / 0 \cdot 60) \\
-(0 / 0 \cdot 18) \\
-(0 / 0 \cdot 13) \\
294(10 / 3 \cdot 40) \\
-(0 / 0 \cdot 49) \\
3200(7 / 0 \cdot 22)\end{array}$ & $\begin{array}{c}(0-615) \\
(0-2072) \\
(0-2822) \\
(141-541) \\
(0-759) \\
(1286-6593)\end{array}$ & $\begin{array}{c}47(1 / 2 \cdot 13) \\
162(1 / 0 \cdot 62) \\
212(1 / 0 \cdot 47) \\
88(11 / 12 \cdot 52) \\
266(4 / 1 \cdot 51) \\
455(3 / 0 \cdot 66)\end{array}$ & $\begin{array}{l}(1-262) \\
(4-902) \\
(5-1182) \\
(44-157) \\
(72-680) \\
(94-1328)\end{array}$ & $\begin{array}{l}-(0 / 0.28) \\
-(0 / 0.08) \\
-(0 / 0.06) \\
-(0 / 1.64) \\
-(0 / 0.05) \\
-(0 / 0.03)\end{array}$ & $\begin{array}{l}(0-1315) \\
(0-4662) \\
(0-5851) \\
(0-225) \\
(0-7418) \\
(0-14683)\end{array}$ \\
\hline $\begin{array}{c}\text { and } \\
\text { aleukaemia } \\
\text { All other } \\
\text { cancers }\end{array}$ & $\begin{array}{l}76(1 / 1 \cdot 32) \\
48(7 / 14 \cdot 6)\end{array}$ & $\begin{array}{l}(2-421) \\
(19-99)\end{array}$ & $\begin{array}{r}356(1 / 0 \cdot 28) \\
64(2 / 3 \cdot 11)\end{array}$ & $\begin{array}{l}(9-1983) \\
(7-232)\end{array}$ & $\begin{array}{l}-(0 / 1 \cdot 04) \\
44(5 / 11 \cdot 45)\end{array}$ & $\begin{array}{r}(0-354) \\
(14-102)\end{array}$ & $\begin{array}{l}-(0 / 0 \cdot 22) \\
-(0 / 1 \cdot 90)\end{array}$ & $\begin{array}{l}(0-1645) \\
(0-194)\end{array}$ \\
\hline
\end{tabular}

*Cause of death included in 'All other cancers' category if observed $=0$; $p$-y $=$ person-years.

1138$, Obs $=10,95 \%$ CI $546-2093)$.

The SMRs for MBT employees with PAB exposed job assignments were significantly increased for all cancers $(\mathrm{SMR}=238$, Obs $=20$, $95 \% \mathrm{CI}=145-367)$, lung cancer $(\mathrm{SMR}=$ 294 , Obs $=10,95 \%$ CI 141-541), and bladder cancer $(\mathrm{SMR}=3200$, Obs $=7,95 \%$ CI 1286 6593). There were no deaths due to prostate cancer (expected $=0 \cdot 49$ ).

The SMRs for MBT employees without job assignments with exposure to PAB were slightly lower than expected for all cancers $(\mathrm{SMR}=86$, Obs $=26,95 \%$ CI 56-125), but were increased for bladder cancer $(\mathrm{SMR}=455$, Obs $=3,95 \% \mathrm{CI}$ 94-1328) and prostate cancer $(\mathrm{SMR}=266, \mathrm{Obs}=$ $4,95 \%$ CI $72-680$ ). The SMR for lung cancer was lower than expected $(\mathrm{SMR}=88$, Obs $=11,95 \%$ CI 44-157).
Table 3 shows SMRs for MBT employees hired in 1956 or later. The total number of deaths from all causes was significantly lower than expected $(\mathrm{SMR}=37, \mathrm{Obs}=8,95 \% \mathrm{CI}=16-72)$, and there were no deaths due to cancer (expected $=4 \cdot 26$ ), or bladder cancer (expected $=0.03$ ).

Table 4 shows SMRs by cumulative exposure for all cancers, lung, prostate, and bladder cancers. The SMRs for all cancers and lung cancer varied around 100 with no trend with exposure. The SMRs for prostate cancer were greater than 200 for non-MBT workers and the three exposure categories, although the $95 \%$ CIs included 100 . The SMRs for bladder cancer were slightly higher in the internal unexposed group $(\mathrm{SMR}=174, \mathrm{Obs}=1$, 95\% CI 4-967) and showed no deaths in the low cumulative exposure group (expected $=0 \cdot 15$ ), and were increased in the medium $(\mathrm{SMR}=623, \mathrm{Obs}=$

Table 4 Standardised mortality ratios for selected causes of death among white hourly male employees exposed to MBT at the Nitro plant 1955-1977 by cumulative exposure with test for trend

\begin{tabular}{|c|c|c|c|c|c|}
\hline & \multirow[b]{2}{*}{ Internal control } & \multicolumn{4}{|c|}{$\begin{array}{l}\text { Cumulative exposure to } M B T \text { (in } \mathrm{mg} / \mathrm{m}^{3} \text { y) } \\
\text { in employees without } P A B \text { job assignment }\end{array}$} \\
\hline & & $<2$ (low) & $2-7.9$ (medium) & $8-129$ (high) & Trend test \\
\hline $\begin{array}{l}\text { All cancers: } \\
\text { SMR (obs/exp) } \\
(95 \% \text { CI })\end{array}$ & $\begin{array}{c}106\left(\begin{array}{c}(23 / 21 \cdot 76) \\
(67-159)\end{array}\right.\end{array}$ & $\begin{array}{c}45(3 / 6 \cdot 62) \\
(9-132)\end{array}$ & $\begin{array}{r}136(12 / 8 \cdot 82) \\
(70-238)\end{array}$ & 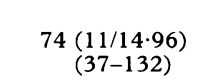 & $\mathrm{p}_{\mathrm{TREND}}=0.36$ \\
\hline $\begin{array}{l}\text { Lung cancer: } \\
\text { SMR (obs/exp) } \\
(95 \% \text { CI) }\end{array}$ & $\begin{array}{c}98(8 / 8 \cdot 16) \\
(42-193)\end{array}$ & $\begin{array}{r}38(1 / 2 \cdot 63) \\
(1-212)\end{array}$ & $\begin{array}{c}135(5 / 3 \cdot 72) \\
\quad(44-314)\end{array}$ & $\begin{array}{c}81(5 / 6 \cdot 18) \\
(26-189)\end{array}$ & $\mathrm{p}_{\mathrm{TREND}}=0.77$ \\
\hline $\begin{array}{l}\text { Prostate cancer: } \\
\text { SMR (obs/exp) } \\
(95 \% \text { CI })\end{array}$ & $\begin{aligned} 205 & (3 / 1 \cdot 47) \\
& (42-598)\end{aligned}$ & $\begin{aligned} & 299(1 / 0 \cdot 33) \\
&(8-1669)\end{aligned}$ & $\begin{aligned} & 286(1 / 0 \cdot 35) \\
&(7-1591)\end{aligned}$ & $\begin{aligned} 243 & (2 / 0 \cdot 82) \\
& (29-879)\end{aligned}$ & $\mathrm{p}_{\text {TREND }}=0.94$ \\
\hline $\begin{array}{l}\text { Bladder cancer: } \\
\text { SMR (obs/exp) } \\
(95 \% \mathrm{CI})\end{array}$ & $\begin{array}{r}174(1 / 0.58) \\
(4-967)\end{array}$ & $\begin{array}{l}(0 / 0 \cdot 15) \\
(0-2455)\end{array}$ & $\begin{aligned} 623 & (1 / 0 \cdot 16) \\
& (16-3473)\end{aligned}$ & $\begin{aligned} & 573(2 / 0.35) \\
&(69-2069)\end{aligned}$ & $\mathrm{p}_{\text {TREND }}=0.31$ \\
\hline $\begin{array}{l}\text { Persons at risk } \\
\text { Person-years at risk }\end{array}$ & $\begin{array}{r}721 \\
9064\end{array}$ & $\begin{array}{r}366 \\
3344\end{array}$ & $\begin{array}{r}257 \\
3956\end{array}$ & $\begin{array}{r}171 \\
4299\end{array}$ & \\
\hline
\end{tabular}


1, 95\% CI 16-3473) and high CE categories (SMR $=573$, Obs $=2,95 \%$ CI 69-2069). Trend tests were not statistically significant. The $R_{R_{M-H}}$ for bladder cancer with the internal comparison population as the standard were 0 for the low cumulative exposure category, $4 \cdot 10$ for the medium cumulative exposure category $(95 \%$ CI $0 \cdot 11-150 \cdot 47$ ), and 3.21 for the high cumulative exposure category $(95 \%$ CI $0 \cdot 22-86 \cdot 23)$. The trend test was not statistically significant $(p=$ $0 \cdot 26)$.

All three deaths from bladder cancer in the MBT group occurred 20 or more years after first exposure. The SMR for all cumulative exposure groups combined in the 20 years or more since first exposure was 545, (95\% CI 112-1591). The SMR for bladder cancer was 363 for the internal unexposed group after 20 or more years since first employment (Obs $=1,95 \%$ CI 9-2024), 0 in the low cumulative exposure group $(\operatorname{Exp}=0 \cdot 12), 792$ in the medium cumulative exposure group (Obs = $1,95 \%$ CI 20-4415) and 655 in the high cumulative exposure group (Obs $=2,95 \%$ CI 79-2367). Confidence intervals in the cumulative exposure analyses indicated imprecise estimates of the SMR by exposure category.

\section{Discussion}

There were no associations between exposure to MBT and its derivatives and increased rates of most malignant neoplasms in employees without a job assignment with exposure to PAB. The SMRs were increased for prostate and bladder cancer. Prostate cancer was high in all cumulative exposure categories and an unexposed internal comparison group. These results suggested that the findings for prostate cancer were related to some extraneous personal or occupational factor that was affecting all groups equally.

The association between exposure to MBT and bladder cancer was based on only three deaths and was very imprecise. There was no strong trend of increasing rates with increasing exposure, although there were too few deaths for meaningful trend analysis. All three deaths from bladder cancer in the group exposed to MBT occurred in the two highest cumulative exposure categories, and with at least 20 years since first exposure.

Evaluation of bladder cancer results for MBT may also have been confounded by exposure to $\mathrm{PAB}$, even though these findings related to workers never assigned to PAB departments. The processes involving PAB and MBT overlapped for a 25 year period and workers exposed to MBT may have had undocumented exposure to PAB if they had a job working in many parts of the plant between 1935 and 1955. Analysis of the MBT cohort hired after the end of work with PAB showed no deaths due to bladder cancer although only 0.03 deaths were expected.

Review of the work histories of the three employees exposed to MBT who died of bladder cancer showed that all held plant wide jobs during the period of PAB use at the plant. Two employees worked one month in either yard labour or a general production job before 1956, and a third employee worked for 10 years before 1956 as a maintenance worker. Whereas very short term exposure to PAB would seem unlikely to be of aetiological importance, a previous report also suggested that a relatively short exposure to PAB may have been related to bladder cancer. ${ }^{14}$

A study at a rubber chemicals factory in North Wales also examined the association between exposure to MBT and bladder cancer. ${ }^{4}$ There were three deaths from bladder cancer among MBT workers at this plant $(S M R=271$, Obs $=3,95 \%$ CI 60-792). One death was in the low cumulative exposure category $(\mathrm{SMR}=184$, Obs $=1,95 \% \mathrm{CI}$ 5-1024), two deaths were in the medium category $(\mathrm{SMR}=561, \mathrm{Obs}=2,95 \%$ CI 68-2028), and there were no deaths in the high category (expected $=0 \cdot 20$ ). The internal unexposed group had a bladder cancer SMR of 80 (Obs $=6,95 \%$ CI 29-174). The authors raised concern about potential confounding exposures for these workers as other substances-namely, phenyl- $\beta$-naphthylamine, o-toluidine, and aniline when evaluated separately, were also associated with increased rates of bladder cancer in exposed subcohorts.

Possible confounding by cigarette smoking was also considered in our study. Cigarette smoking has been shown to be associated with a two to fourfold risk of bladder cancer among male smokers compared with non-smokers. ${ }^{15} 16$ The effect of cigarette smoking as a confounding variable was indirectly evaluated by the method of Axelson, ${ }^{17}$ as smoking data was unavailable for the plant population. These results indicated that cigarette smoking would only explain up to a $20 \%$ increase in the SMR for this study population.

A major limitation of the investigations at both the West Virginia and North Wales plants is the small number of deaths from bladder cancer in the cohorts. The results of both studies may also have been influenced by the presence of overlapping confounding exposures that were found to be associated with increased rates of bladder cancer. Future study updates of the group of employees hired after 1955 at the West Virginia plant and of the North Wales cohort should provide more definitive information as to whether there is an association between MBT and increased rates of bladder cancer. 


\section{Conclusion}

An excess of bladder cancer was seen for MBT workers who also had job assignments with exposure to PAB. For MBT workers who did not have a job assignment with exposure to $\mathrm{PAB}$, there were no excesses for most malignant neoplasms. The SMR for bladder cancer was raised, although there were too few deaths to evaluate trends by exposure category. The possibility of confounding by PAB for MBT workers who had plant wide jobs not directly related to departments with exposure to PAB must be considered in the light of the potency of PAB as a bladder carcinogen. There were no deaths from bladder cancer among MBT workers hired after the end of PAB use at the plant although only 0.03 deaths were expected.

This work was sponsored by Monsanto Company, 800 North Lindbergh Boulevard, St Louis, Missouri 63167

1 National Toxicology Program: toxicology and carcinogenesis studies of 2-mercaptobenzothiazole (CAS No 149-30-4) in F344/N Rats and $B_{6} \mathrm{C}_{3} \mathrm{~F}$ Mice. Draft Report. NTPTR 332. Research Triangle Park, NC: NIH publication 1987. No 87-2588.

2 Ogawa Y, Kamato E, Suzuki S, et al. Toxicity of 2-mercaptobenzothiazole in mice. Eisei Shikenjo Hokoku 1989;107: 45-50.

3 United States Department of Health and Human Services. Sixth annual report on carcinogens, Summary 1991. Washington, DC: USDHHS, 1991.
4 Sorahan T, Pope D. Mortality study of workers employed at a plant manufacturing chemicals for the rubber industry: 1955-86. Br F Ind Med 1993;50:(in press).

5 US Department of Health, Education and Welfare. Eighth Revision, International Classification of Diseases, adapted for use in the United States USDHEW, Washington, DC. 1968. (US Public Health Service publication No 1693).

6 Adachi T, Tanaki A, Yamaha T. Adsorption, distribution, metabolism and excretion of $\mathrm{N}$-cyclohexyl-2-benzothiazylsulfenamide (CBS), a vulcanizing accelerator, in rats. Radioisotopes 1989;38:255-8.

7 El Dareer SM, Kalin JR, Tillery KF, Hill DL, Barnett Jr JW. Disposition of 2-mercaptobenzothiazole and 2-mercaptobenzothiazole disulfide in rats dosed intravenously, orally, and topically and in guinea pigs dosed topically. $\mathcal{F}$ Toxicol Environ Health 1989;27:64-84.

8 Nagamatsu K, Kido Y, Urakubo G, Aida Y, Ikeda Y, Suzuki Y. et al. Absorption, distribution, excretion and metabolism of 2 -mercaptobenzothiazole in guinea pigs. Eisei Kagku 1979;25:59-65.

9 Melick WF. First reported cases of human bladder tumors due to a new carcinogen-xenylamine. F Urol 1955;74:760-6.

10 Collins JJ, Strauss ME, Levinskas GJ Conner PR. The Mortality experience of workers exposed to 2,3,7,8-tetrachlorodibenzo-p-dioxin in a trichlorophenol process accident. Epidemiology 1993;4:7-13

11 Marsh GM, Preininger M. OCMAP. A User-oriented occupational cohort mortality analysis program. The American Statistician 1980;34:245.

12 Rothman KJ, Boice JD. Epidemiologic analysis with a programmable calculator. Boston: Epidemiology Resources Inc, 1982.

13 Breslow NE, Day NE. Statistical methods in cancer research: Vol II-The design and analysis of cohort studies. Lyon: International Agency for Research on Cancer, 1987. (IARC sci pub No 82.)

14 Melick WF, Naryka JJ, Kelly RE. Bladder cancer due to exposure to para-aminobiphenyl: a 17-year follow-up. $f$ Urol 1971;106:220-6.

15 Cole P. Lower urinary tract. In: Schottenfeld D, ed. Cancer epidemiology and prevention-current concepts. Springfield, IL: CC Thomas, 1982.

16 Matanoski GM, Elliott EA. Bladder cancer epidemiology. Epidemiol Rev 1981;3:203-29.

17 Axelson O. Aspects on confounding in occupational health epidemiology. Scand $\mathcal{F}$ Work Environ Health 1978;4:85-9.

Accepted 18 January 1993 